\title{
ENGLISH SUMMARY
}

The Swedish Institute for Children's Books publishes Barnboken - Children's Books semiannually. It contains articles and essays on children's literature by specialists in the field, and provides information on reference books and theoretical works recently published and acquired by the library of the Institute.

Jane Doonan: Songs from the ghetto: Brundibár retold by Tony Kushner, illustrations by Maurice Sendak, after the opera by Hans Krása and Adolf Hoffmeister.

The essay discusses the aesthetics and the visual design of Brundibar, for which Sendak constructed a dual narrative with a holocaust theme. Consideration is given to some of the problems faced by Sendak, and his pictorial solutions. The main focus is on the means of representation, including lettering, setting, and images around which the dual narrative is constructed, as well as borders and external and internal peritexts.

Lars Wolf: The dog and the star: Reading Henning Mankell's Joel books

This article is a study of the development of a literary character from childhood to manhood, as portrayed by Henning Mankell in two books for young adult readers. It points out the most characteristic traits of the protagonist, explaining them on the basis of his social environment.
Wiveca Friman: Once upon a time a girl was raped: Themes and narrative techniques in Med Maris ögon (Through Mari's Eyes) and Ave Eva

This article is an analysis of two texts, both of which have rape as a theme. The results indicate the ways in which each author uses a framework narrative by way of which a young girl narrates the dramatic events in her life. Casta makes his message clear by using intertexts, while Hind focuses primarily on relations and society.

Carina Andersson, Charlotte Lindgren, Catherine Renaud: What a mess on the kitchen settee! Translating children's books: a contemporary Swedish-French perspective

Although very few French children's books are translated into Swedish, quite a large number go in the opposite direction. This article describes the ways in which Swedish children's books are adapted to the French target culture, in terms of linguistic as well as literary sociological categories. It also deals with specific translation problems, and describes the ways in which illustrations can both pose special challenges to the translator and save the day. 